\title{
LA TRAZA DEL RETABLO DE SANTA TERESA DE PUEBLA EN 1626
}

\section{Por Efrain Castro Morales}

El convento de San José de carmelitas descalzas, conocido casi desde su fundación como de Santa Teresa, es el cuarto monasterio de la ciudad de Puebla, la primera fundación de monjas carmelitas en Nueva España, y también el primero que tuvo una iglesia cubierta de bóvedas y cúpulas, no con techo de madera como los demás de la ciudad de los Ángeles.

Su iglesia "una de las mejores y más fuertes que hay en las Indias" fue contratada en 1618, con el arquitecto Francisco de Aguilar, por entonces alguacil mayor de Cholula, que venía construyendo el convento y debió terminarse dos años más tarde; encargándose de maestrar la obra el alarife Juan Díaz Cabañas; tuvo un costo de 28,680 pesos y 4 tomines de oro. ${ }^{1}$ Señalando una pauta en la evolución arquitectónica de la región poblana.

No sabemos con precisión la fecha en que fue consagrada, pero sí podemos suponer que se realizo antes de que la obra y particularmente la decoración del interior se terminase. El 15 de enero de 1626, ante el escribano Diego Corona Vázquez, se presentaron Pedro Miranda y Alonso Fernández de Miranda, hermanos y vecinos de la ciudad, para contratar con el escultor y ensamblador, Francisco de la Gándara y Hermosa, y con el dorador José de Cuellar, la obra de un retablo y sagrario para el altar mayor de esta iglesia. ${ }^{2}$

En la escritura quedaron bien señaladas las condiciones para realizar este retablo, que debería ser de madera de ayacahuite seca y "los eligimentos de pino, por ser de madera más fuerte"; siguiendo la traza, así en "architectura, como de escultura y talla", agregando los guardapolvos que no se habian señalado en ella.

Llevaria esculturas y tableros, con pinturas, que deberian colocar los mencionados Pedro Miranda y su hermano. Especificándose que las "cajas" de San José y un Cristo, serían como las pidieren los mencionados hermanos; el dorador quedaba comprometido a "dorar, estofar y encarnar las columnas y jaspeallas", así como el resto del retablo y sa-

1 Arch. Gral. de Notarias, Puebla: Nota. 4:1618: (TV-16) .

2 Arch. Gral. de Notarlas, Puebla: Nota 3:1626:93. 
grario, que seria estofado "a punto de pincel", con toda su talla "adornada y ricamente vestida, y granida... de colores de Castilla, que no lleve pan de plata, ni esmalte, y las encarnaciones al natural o al polimento, según pidiere".

El costo del retablo era de 5,500 pesos de oro común, de los cuales se entregarían de inmediato 1,000 para la madera, al año próximo otros $1,000 \mathrm{y}$ al siguiente otra cantidad igual, pagándose el resto en los cuatro años siguientes, de tal manera que el total quedaría cubierto en seis. A pesar del plazo tan largo para la liquidación de esta obra, quizá por la pobreza del convento, debería estar "acabada de todo punto y asentada" dos años después de la fecha de la escritura.

Seguramente fue terminado y colocado en la fecha especificada, pero no sucedió así con lo que se deberla pagar a los artistas, ya que el año de 1638, Francisco de la Gándara, solicitó en el mes de julio, al alcalde ordinario de la ciudad, un traslado de la escritura. En septiembre de ese mismo año fue presentada por Diego Bonilla, procurador de la audiencia ordinaria, en nombre de Francisco de la Gándara, con una petición para que se librase mandamiento para ejecutar las personas $y$ bienes de Pedro de Miranda y Alonso Fernández de Miranda, por la cantidad de 627 pesos de oro común, que aún le adeudaban. El procurador de causas Francisco de Valdivia, en nombre de los deudores, se opuso a la ejecución unos días después, alegando ser injusta, ya que no se habla presentado por "parte legitima, ni contra parte obligada en tiempo, ni en forma, ni en virtud de pedimento que la truxese aparejada", señalando además "la malicia del dicho Francisco de la Gándara" porque existía una cédula de finiquito por él y varios testigos.

Este finiquito, al parecer otorgado por ambas partes, en 15 de septiembre de 1631, daba por terminado el contrato de la obra del retablo, apareciendo el escultor como deudor de una cantidad menor, 48 pesos, que se obligaba a pagar con la hechura de un "Cristo de naranjo".

De la Gándara, sin embargo no era de este parecer, declarando ante el alcalde Marcos Rodríguez Zapata, "que la cédula, ajustamiento y finiquito es falso y tal no ha hecho y la firma questa al pie de dicho ajustamiento no es suya, ni tal ha hechado y es contrahecha a la suya". Después de varios plazos otorgados por el alcalde para que presentasen pruebas al respecto, en mayo de 1639 se notificó a las partes que el termino otorgado habia concluido, y el procurador Diego Bonilla, presento un alegato, en que señalaba entre otros puntos, que el finiquito era falso, además, de que Francisco de la Gándara el día de la fecha de 
éste, se encontraba en la ciudad de México, demostrando esto con una escritura otorgada en México, ante el escribano real Alonso de la Cueva; impugnando a los testigos citados, que no tenian "ni mayoria, ni exepción que se requiere, porque todos ellos son personas muy de casa del dicho Alonso Fernández". Como pruebas aportó la escritura otorgada en México - un poder a favor Pedro Escudero para algunas cobranzasante Alonso de la Cueva, y para el cotejo de la firma la traza original del retablo fabricado, rubricada por las dos partes.

El expediente termina con una solicitud por parte del escultor, pidiendo que "a su derecho conviene se le concedan cuatro días más de término para probar en razón de lo que tiene pedido" y el acuerdo del alcalde, favorable al caso. ${ }^{3} \mathrm{La}$ resolución final se desconoce.

Este retablo al igual que la iglesia de Santa Teresa, es de especial importancia para la historia del arte novohispano, pero tiene la misma suerte de casi todos los retablos de la primera mitad del siglo xvir. En 1675, se le describe como "de talla y pincel, a lo moderno, bien costoso, y tan grande, que ocupa toda la testera de alto a baxo; y en el lugar principal está el glorioso Patriarca San Joseph, de bulto, sentado en una silla con el Niño Jesús en los brazos". " Más tarde, en 1732, sabemos que: "hasta el año de mil seiscientos y ochenta y nueve, duró el colateral y altar mayor, que costeó don Andrés de Arano, que por estar ya viejo y deslustrado instó al licenciado don Alonso Berruecos de Arellano, capellán de este convento, en que hiciese otro nuevo al uso, ofreciendo ayuda a su costo, y con efecto siendo priora la madre Maria de Christo, (por) segunda vez, se dio principio a su hermosa fábrica, acabándose el primer cuerpo que se colocó en blanco, llegando su costo a más de dos mil pesos; pasados algunos años se ofreció costear toda su primorosa architectura, correspondiente a lo que demandaba el primer cuerpo, el se-

SExecución 1638. Francisco de la Gándara Hermosa contra Alonso Ferndndez de Miranda, por pesos de oro. Juez el Capitdn Juan de Vargas. Escribano Alonso Corona. Archivo Judicial en el Instituto Poblano de Antropologia e Historia.

4 "Vida de la Vble. Madre Isabel de la Encarnación, carmelita descalza, natural de la Ciudad de los Angeles. Sale a luz a cuidado de la Cesdrea, Nobilisima Ciudad de la Puebla de los Angeles. Compúsola el Licenciado Pedro Salmerón Presbitero natural de esta Ciudad. Dedicase, al Glorioso Patriarca S. Joseph. Patrón universal deste Reyno, y particular desta Ciudad. Año de 1675. Con licencia, en México por Francisco Rodriguez Lupercio, en la fuente de Palacio." f. 5. vto. 
ñor canónigo y ya meritisimo Maestre Escuela de esta Santa Iglesia Cathedral, doctor don Diego Sánchez Peláez, y con efecto costando y asistiendo personalmente a la obra, concluyó y acabó todo el altar mayor, buscando y solicitando el oro de más precio para dorarlo, gastando más de doce mil pesos, hasta que se dedicó el año de mil seiscientos y noventa y ocho..." Este retablo, de columnas salomónicas, tuvo la misma suerte, así ya a finales del siglo xvni, Fernández de Echeverría y Veytia al describir la iglesia comenta: "el altar mayor y los del cuerpo de la iglesia están adornados de retablos muy buenos aunque antiguos", " siendo destruidos poco después para colocar otros altares con pilastras estípites, que desaparecieron el siglo xix, para dar lugar a otros "modernos", que son los adefesios neoclásicos que se conservaban hasta ahora.

Sólo nos queda lamentarnos del gusto por la "renovación" de los poblanos y consolarnos con la documentación acerca de estas magníficas obras de arte.

Así podemos saber algo acerca de su autor Francisco de la Gándara y Hermosa, tan poco conocido, como sucede con casi todos los artistas, particularmente escultores, que trabajan en Nueva España durante la primera mitad del siglo xvır. Quizá este artista sea el escultor "Gándara", que figura entre 1619 y 1625 , en Nueva Galicia, interviniendo en la restauración de la escultura de la Virgen de San Juan de los Lagos, · ya que al parecer es uno de los últimos artistas trahumantes que recorren

5 Fundación, y primer siglo del muy Religioso Convento de Sr. S. Joseph de Reli. giosas Carmelitas descalzas de la Ciudad de la Puebla de los Angeles, en la Nueva España, el primero que se fundó en la América Septentrional, en 27 de Diciembre de 1604. Gobernando este Obispado el Ilustrisimo Señor Doctor D. Diego Romano quien lo erigio, y fundó, en virtud de Breve Apostólico de N.S.P. Clemente VII, que con la subscripción de capitulo 25, del Libro 12, del tomo tercero, de la Reforma de las Descalzas de Nuestra Señora del Carmen de la primitiva observancia, hecha por Santa Theresa De Jesu's, en la antiquissima Religion, fundada por el grande Propheta Elias. Escribe y saca a Iuz. El Dr. D. Joseph Gómez de la Parra, Angelopolitano, Colegial del Maior de Santos, Magistral en la Santa Iglesia de Michoacán, y después en esta de la Puebla, electo Maestre Escuela, Examinador Synodal en los dos Obispados, Cathedrático de Prima de Theología en los Reales Colegios de S. Pedro. y S. Juan de esta Ciudad, y Regente de sus Estudios. $Y$ por su fallecimiento, proseguida, por el Doctor D. Joseph Martínez de la Parra, Decano de la facultad de Sagrada Theología, y Calificador del Santo Officio de la Inquisición de este Reyno. Dedicada por las religiosas de este convento, a Nuestra Sra. de el Carmen: Con licencia de los superiores: en la Puebla de los Ángeles, por la Viuda de Miguel de Ortega, en el Portal de las Flores, Año de 1732." pp. 67 y 68.

- Ferndndez de Echeverria y Veytia, Mariano. - "Historia de la Fundación de la Ciudad de la Puebla de los Angeles en la Nueva España. Su descripción y presente estado". (México, 1931), t. II, p. 512.

7 Toussaint, Manuel, Arte colonial en México, (México, 1948), pp. 167 y 228. 
la Nueva España y que en el florecimiento del barroco no se encuentran más que sólo en las ciudades de importancia.

La primera noticia que tenemos de este escultor en la ciudad de Puebla se refiere a la venta de un esclavo en el mes de abril de 1609 , donde figura ya como vecino de la ciudad. ${ }^{8}$

Al año siguiente, Juan Bautista Gómez, maestro ensamblador y carpintero, residente en Puebla, se obligó a trabajar y asistir, junto con su aprendiz Juan Bautista de Figueroa, de 17 a 18 años de edad, natural de Triana, en todas las obras de carpintería y ensamblaje que le mandase de la Gándara, por espacio de un año. ${ }^{9}$ Por cierto que el aprendiz, unos meses más tarde, fue colocado por su curador con de la Gándara, porque el maestro ensamblador se había ausentado de la ciudad. 10 También en ese mismo año figura por su aprendiz, por espacio de tres años y medio, Juan Quintana. ${ }^{11}$

En 22 de abril de 1610, junto con Alonso Gutiérrez, ensamblador y vecino de la ciudad, se concertó para formar una compañia para realizar obras de ensamblaje, talla y escultura "de las que hubiere en el pueblo de Cachula (actual Quecholac) y seis leguas en contorno", por espacio de 6 años, particularmente un retablo para Juan de Peralta, gobernador de dicho pueblo, que tenía contratado en 400 pesos. Gutiérrez debería permanecer en el pueblo durante los 6 años, acudiendo con la herramienta el maestro de la Gándara. ${ }^{12}$

Por cierto, en mayo, el pintor Juan de Fonseca, contrató con de la Gándara el dorado, pintura y estofado de ese retablo, aś como las pinturas de otro para el pueblo de Orizaba. ${ }^{13}$

En Puebla, en ese mismo año, concertó con el contador Marcos Rodríguez, escribano mayor del cabildo, un retablo y una reja para su capilla en la iglesia de Santo Domingo, por entonces en construcción. Este retablo debería tener 12 pies de ancho por 7 de alto "o más si cupiere", con cuatro columnas corintias de fuste estriado en el primer cuerpo, cuatro niños "de excultura que sobrecarguen las columnas, sagrario al centro y a los lados los retratos de Marcos Rodríguez Zapata y doña Clara Cerón; en el centro en un "encasamiento con su venera" la virgen de Atocha, a quien se encontraba dedicada la capilla, y en los

8 Arch. Gral. de Notarias, Puebla: Not. 3:1609:841.

O Arch. Gral. de Notarías, Puebla: Not. 3:1610:540 vto.

10 lbid., 1311.

11 Ibid., 628.

12 Arch. Gral. de Notarías, Puebla: Not. 4:1610 (I): (VI-22).

13 Arch. Gral. de Notarías, Puebla: Not. 3:1610.945. 
lados, tableros con pinturas, que representaban a Santa Catalina y Santa Clara y encima de estos "un cuadrito de media figura; el segundo cuerpo de "orden composita con talla", con dos ángeles "de escultura". Deberia entregarse en 8 meses, pagándose por la obra la cantidad de 1,100 pesos de oro común. ${ }^{14}$

También para el convento de Santo Domingo, en la capilla de Pedro Hernández Asperilla, se obligó a hacer un retablo, igual al de la capilla de Pedro Esteban "mudando sólo los nombres de los santos. ${ }^{15}$ El retablo de Pedro Esteban, lo habian realizado en 1605, Juan Salguero Saavedra, maestro Arquitecto y escultor, el dorador Juan de la Torre y el pintor Luis Acevedo, y estaba dedicado a San Raimundo. ${ }^{16}$ La reja de la capilla, de madera dorada, sería como la de la capilla de San Jacinto de la misma iglesia".

Durante algunos años deja de figurar en Puebla y no es, sino hasta 1613, en que aparece nuevamente, al contraer matrimonio con doña Maria de Mendoza, natural de esta ciudad, hija de Baltazar González Guerrero y Ana Rodríguez de Mendoza, otorgando el recibo de una cuantiosa dote. 17

En febrero de 1615, en el pueblo de Tehuacán firmaron una escritura de concierto, el padre fray Felipe López, guardián del convento de San Francisco y Cristóbal Ramirez de Mayorga, síndico del mismo, para fabricar el retablo mayor de su iglesia que tenían "tratado y concertado con intervención del padre fray Juan de Torquemada, maestro provincial de la dicha orden y comisario general". Las condiciones para hacer este retablo fueron las siguientes:

"Primeramente ha de tener de alto este retablo, desde encima del altar hasta lo más alto del remate, cuarenta y cinco pies de a tercia y de ancho, buscando su ochavo de la planta de la capilla, treinta y ocho. Ha de ser de tres cuerpos con su remate, como por la traza parece, que ha de ir firmada de su paternidad el padre provincial. La primera orden ha de ser dórica, la segunda de orden jónica, la tercera de orden corintia. El primer cuerpo ha de llevar seis columnas y el segundo otras seis y el tercero cuatro, como por la traza se verá y estos tres cuerpos han de alzar con su remate los dichos cuarenta y cinco pies, dando a cada

14 Ibid., 698.

15 Ibid., 960 .

16 Arch. Gral. de Notarias, Puebla: Not. 3:1605:1575.

17 Arch. Gral. de Notarias, Puebla: Not. 4:1613: (XI.7) . 
cuerpo su cornisamento como lo pide cada orden, conforme a buen arte."

"El pedestal de este retablo ha de ir bien elejido y guarnecido, como la orden dórica pide y en él ha de llevar los doce apóstoles, de medio relieve."

"El primer cuerpo dicho ha de llevar a su gueco que hace jamba y por detrás tablero, en que entra el sagrario que está hecho de mano de Francisco de la Gándara, el cual tiene ya entregado, que entra en el concierto desta obra toda."

"Al lado del sagrario entre coluna y coluna hay dos niquios, en cada lado el suyo, en los cuales hay dos figuras de bulto grandes, en cada niquio el suyo, San Francisco al lado del Evangelio y San Josefe a la Epistola, al lado de cada uno destos santos hay, entre coluna y coluna, un tablero de pintura en el cual ha de ir pintada la historia que dicho provincial señalare, de cada parte la suya. Ha de llevar este primer cuerpo dórico su cornisamento con su friso de talla, como la orden dórica pide, estas colunas han de ir estriadas y han de llevar pilastras de la misma orden."

"El segundo cuerpo ha de ser de orden jónica, ha de llevar su sotabanca y en el medio encima del sagrario, ha de llevar una historia de medio relieve de la Limpia Concepción del pueblo. A los lados desta historia a de haber en cada lado un niquio para dos Santos Dotores de la Iglesia, y a los lados de cada uno destos santos ha de haber dos tableros de pincel que han de ser los que su paternidad señalare, como se dijo, acordes a los de abajo, que corresponden a ellos; han de llevar estas colunas jónicas tercios de talla y sus capiteles y sus pilastras, con su cornisamento y friso de talla y guardapolvos como lo pide esta orden jónica."

"El tercero cuerpo ques de orden corintia ha de llevar ast mesmo su sotabanca y enmedio encima de la historia de la Concepción, ha de llevar una caja cuadrada en la cual ha de haber tres figuras de bulto, Xpto, Nuestra Señora y San Juan, al pie de la Cruz, a los lados desta caja hay dos niquios, a cada lado el suyo, que cada uno lleva un Dotor de la Iglesia, de bulto; a los lados de la parte de fuera hay a cada lado un cartón que está tallado y hace remate, que enmedio llevará un óvalo en el cual ha de ir de pintura, con una figura en cada lado, la que su paternidad señalare. Lleva este cuerpo sus colunas corintias, como es dicho, con sus tercios y capiteles tallados y sus pilastras de la mesma 
orden, y su cornisamento con su friso tallado como la dicha orden lo pide, y encima su frontispicio con un Dios Padre, en medio relieve."

"Toda esta obra ha de ir, así de madera, como de dorado y pincel, estofado y encarnado, bien hecha y acabada, como el arte lo requiere y a contento de su paternidad del padre provincial y de maestros peritos en el arte, siendo necesario."

"Es condición que durante el tiempo que durante el dicho retablo que ha de ser, y me obligo del día de la fecha de la escritura en dos años, me ha de dar casa para hacer la dicha obra y de comer a mí y a un oficial español, y un aprendiz, y las maderas necesarias puestas al pie de la obra y clavos, y cuatro indios carpinteros que están obligados en la escritura pasada, y el tiempo que yo faltare en mi lugar pueda dejar un aparejador y le sustenten al tiempo que yo asistiere. Todo esto me obligo a hacer con las condiciones dichas, por precio de cinco mil pesos de oro común, pagados en esta manera: los mil ducientos cincuenta y cinco que tengo recebidos hasta hoy día de la fecha de la escrptura; los mil cuarenta de Alonso Prieto de Bonilla, síndico que fue deste convento, de que le di carta de pago, que esta y las que tengo dadas se entiende ser una misma cosa; ciento de Gil de Ávila, albacea de Alonso Díaz Marcano; y ciento quince de mano de Martín Colchón los cuales le libre entriego en el síndico del convento Xpotobal Ramírez de Mayorga, como parecerá por la libranza; y lo demás hasta ser cumplida la dicha cantidad se me ha de ir dando así como la obra se vaya haciendo."

"Es condición que si por no me dar el dinero para ir haciendo la dicha obra parare, que no se entienda ir corriendo el plazo que esta señalado para cuando lo tengo de entregar, y es condición que para armar el dicho retablo me han de dar andamios y indios que me ayuden a armar el dicho retablo."

"Es condición que una escriptura que está hecha de la madera del dicho retablo que hacer, que se ha buscado no se ha hallado, aunque en algún tiempo parezca no sea ninguna, ni tenga juerga para ninguna de las partes. Fray Juan de Torquemada, Maestro Provincial. Fray Felipe López. Xpotal Ramirez de Mayorga. Francisco de la Gándara Hermosa." 18

Es una pena que no se conozcan los temas de las "historias que señaló Fray Juan de Torquemada, ni se aclare más acerca de los doctores de la Iglesia, porque queda incompleto el sentido de su composición teológica y guarda estrecha relación con la de los grandes reta-

18 Arch. Gral. de Notarias, Puebla: Tehuacán: 1615-22: 5 y 6. 
blos del siglo xvi, en "el magno triángulo total, cuya base son los apóstoles y cuyo vértice es el Dios Padre Todopoderoso". ${ }^{18}$

En mayo de 1616, Francisco de la Gándara Hermosa, como maestro arquitecto y escultor, celebra un contrato con el licenciado Andrés Suárez Parra, abogado de la Real Audiencia de México, para "hacer su orden y traza" de cuatro baños y un "nadadero" en el ojo de San Pablo, "poniendo sólo su maestría". ${ }^{20}$ Dos años más tarde, en compañía del dorador José de Cuellar, se obligó a labrar un retablo y la reja para la capilla de Alonso Téllez, en el convento de San Francisco de Puebla. ${ }^{21}$

Desaparece de Puebla, por lo menos documentalmente, durante algutnos años, lo que nos hace pensar que por entonces trabaje en la ciudad de México y en la Nueva Galicia. En octubre de 1625, figura como vecino de Puebla nuevamente ${ }^{22}$ y al año siguiente contrata el retablo para el convento de Santa Teresa. Por entonces era su aprendiz Simón de Arredondo, natural del pueblo de Bárcena, en las montañas de Burgos. ${ }^{23}$

Por ser quizá más productiva la agricultura que la escultura, se obliga a pagar el arrendamiento de una casa que tuvo en Puebla hasta el año de 1637 , pero ahora no como escultor, sino como vecino y labrador del pueblo de Calpan, 24 donde lo volvemos a encontrar el año de 1641. ${ }^{28}$ Pero todo hace suponer, que aun como labrador no tuvo el éxito y fortuna que esperaba, porque el 7 de junio de 1649 otorgó su testamento "estando como estoy enfermo en cama en este hospital del señor San Pedro". Por este documento sabemos que era hijo legítimo de Pedro de la Gándara y de Catalina de Hermosa, difuntos vecinos que habian sido "del pueblo de Ceceña, en la junta de Gudeño de las montañas de Burgos", de donde era natural. Una de las cláusulas del testamento muestra claramente las malas condiciones económicas en que se encontraba, "declaro debo muchas cantidades de pesos a diferentes personas, que los que son sabe doña María de Mendoza, mi mujer, y de presente no tengo con qué satisfacerlo, $y$ ansí pido y suplico a mis acredores por amor de Dios me perdonen el no pagarles, no es falta de voluntad, sino

19 De la Maza, Francisco, Los retablos dorados de Nueva España, (México, 1950) p. 24 .

20 Arch. Gral. de Notarías, Puebla: Not. 3:1616: (V-11).

21 Arch. Gral. de Notarías, Puebla: Not. 4:1618: (VI-26).

22 Arch. Gral. de Notarías, Puebla: Not. 3: 1625: 1711 .

23 Arch. Gral. de Notarías, Puebla: Not, 4:1626: (VI-19).

24 Arch. Gral. de Notarias, Puebla: Not. 3:1638: 1530.

25 Arch. Gral. de Notarias, Puebla, Not. 8: 1641: 2031. 
mucha pobreza". Algunos otros datos nos aclaran más al respecto, tenia una mina en la Mixteca baja. 26

La obra de Francisco de la Gándara, como la de casi todos los escultores de el primer tercio del siglo xvi, no se conserva. La documentación acerca de los escultores de este periodo, tan importante en la evolución del retablo renacentista hacia el barroco, es abundante, por lo menos en los archivos de la región de Puebla y Tlaxcala, pero las obras desgraciadamente no existen. Así de la Maza, nos dice "no recuerdo que se conserve ningún retablo de la primera mitad del siglo xvir, salvo Tlatelolco, y eso en litografía" ${ }^{27}$ y Bonet Correa también indica "la falta de obras de primer orden" por lo que es difícil seguir esta evolución, siendo necesario acudir a "ejemplos de escasa categoria o un poco alejados geográficamente". ${ }^{28}$ Sólo restan, en muchas ocasiones abandonados en bodegas, fragmentos de columnas, relieves y esculturas aisladas, difíciles de fechar y que nunca podrán dar idea de un retablo completo, concebido como un cuerpo arquitectónico.

E1 desafortunado pleito emprendido por de la Gándara en contra de sus deudores y el juicio por el sospechoso finiquito, para fortuna de la historia del arte colonial de Puebla, permitieron que la traza aportada como prueba se conservase en el expediente del juicio. Así podemos tener idea completa de un retablo del primer tercio del siglo xvir.

La traza incluida en el expediente, mide 648 por $427 \mathrm{~mm}$., dibujada modestamente en dos hojas de papel grueso con tinta café oscura y aguada, nos muestra uno de los tantísimos proyectos que se deberian seguir en la construcción de un retablo. Como se trata de un proyecto, sólo la mitad a lo largo, está completamente dibujada con toda la decoración.

El retablo queda dividido horizontalmente en dos cuerpos y un remate. E1 primero lleva columnas corintias con el fuste liso, al centro, donde firman las partes y el escribano da fe, que "ésta es Ia forma y traza del retablo y sagrario a que se refiere la escritura" se encuentra un espacio para el sagrario, cerrado por un arco de medio punto, que lleva en las

26 Arch. Gral, de Notarías; Puebla: Not. 2: 1638-1715: Testamentos: 42. 27 De la Maza, Francisco, Op. cit., p. 30.

28 Bonet Correa, Antonio, "Retablos del siglo xvin en Puebla", Archiro Español de Arte, t. xxxvi, núum. 149 (Madrid 1968). 

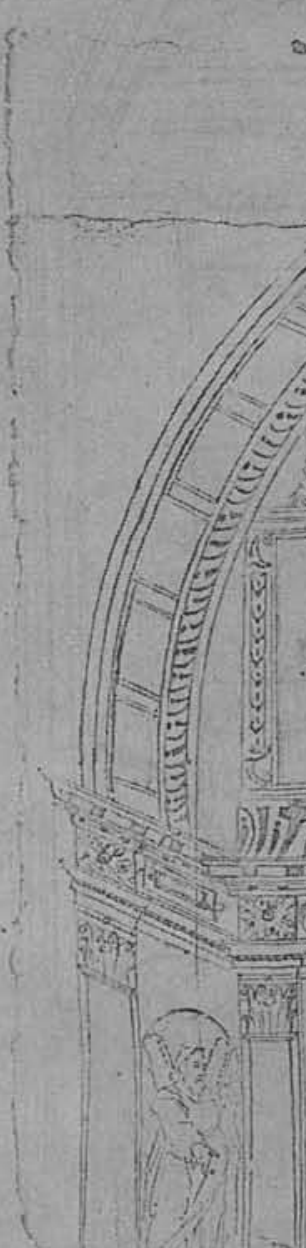

s.
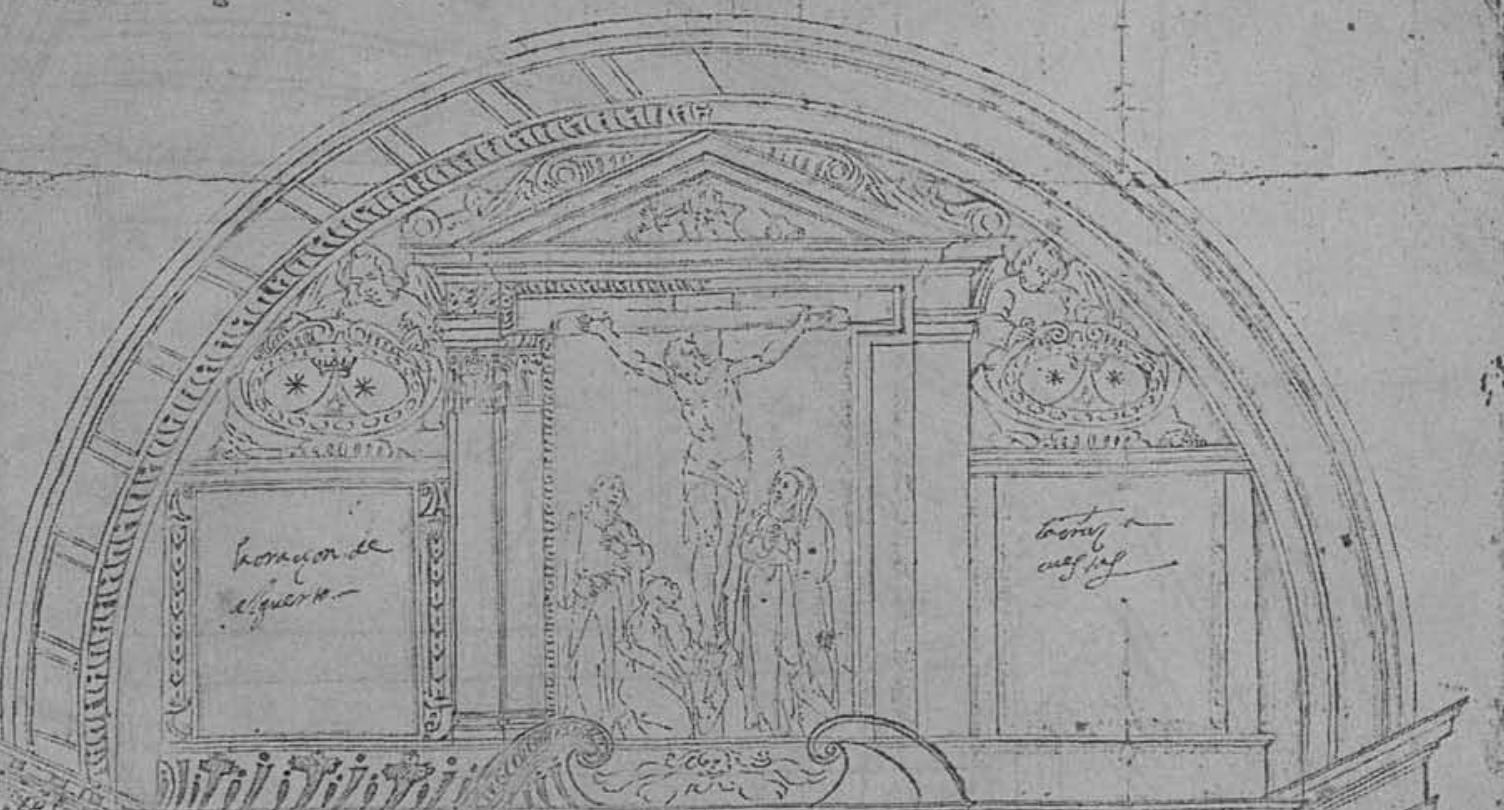

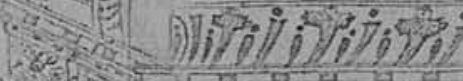

(2) 4 .

$4 \frac{1}{2}$

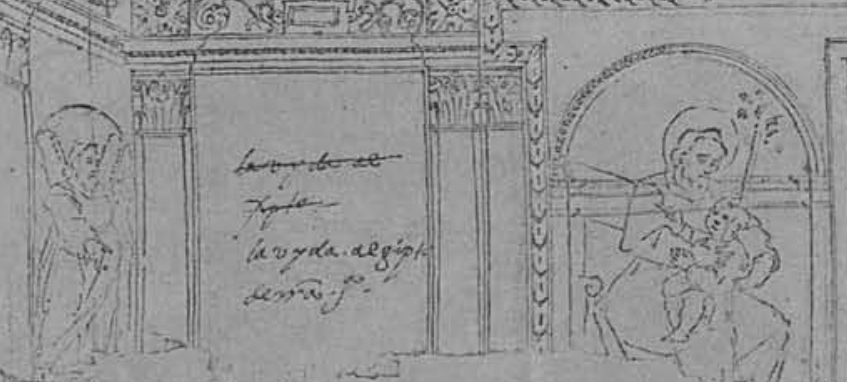

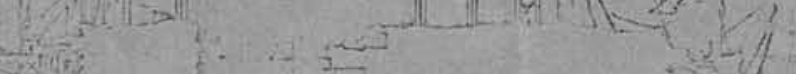

M.

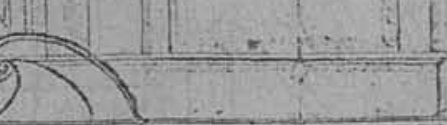

(I) 2 , को
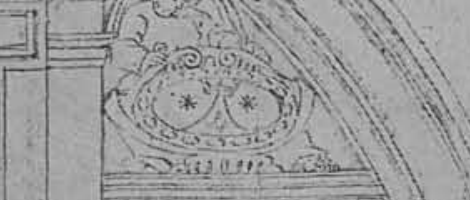
DOI: http://dx.doi.org/10.22201/iie.18703062e.1969.38.887

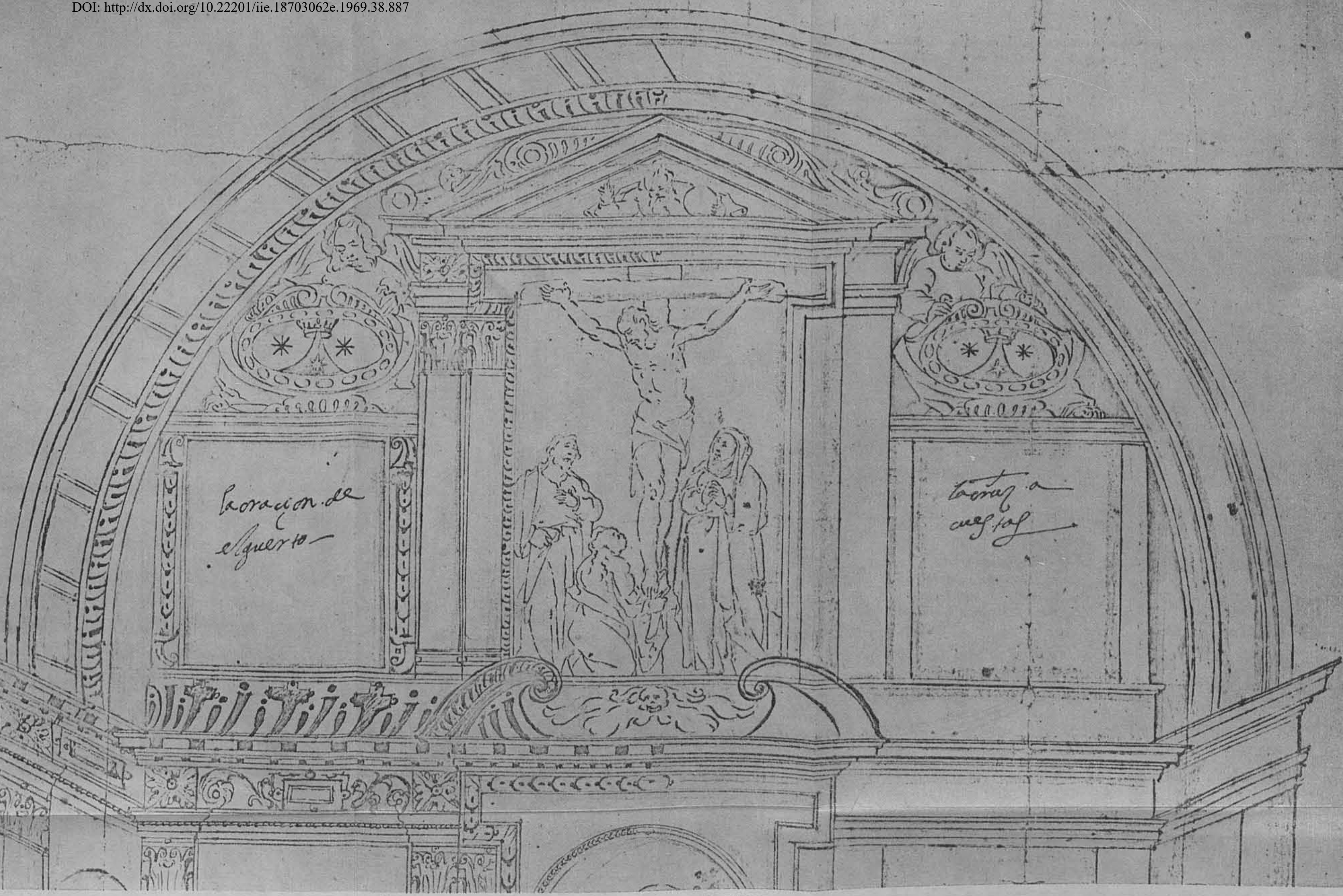
2. Traza del retablo de Santa Teresa de Puebla, 1626. Parte superior 


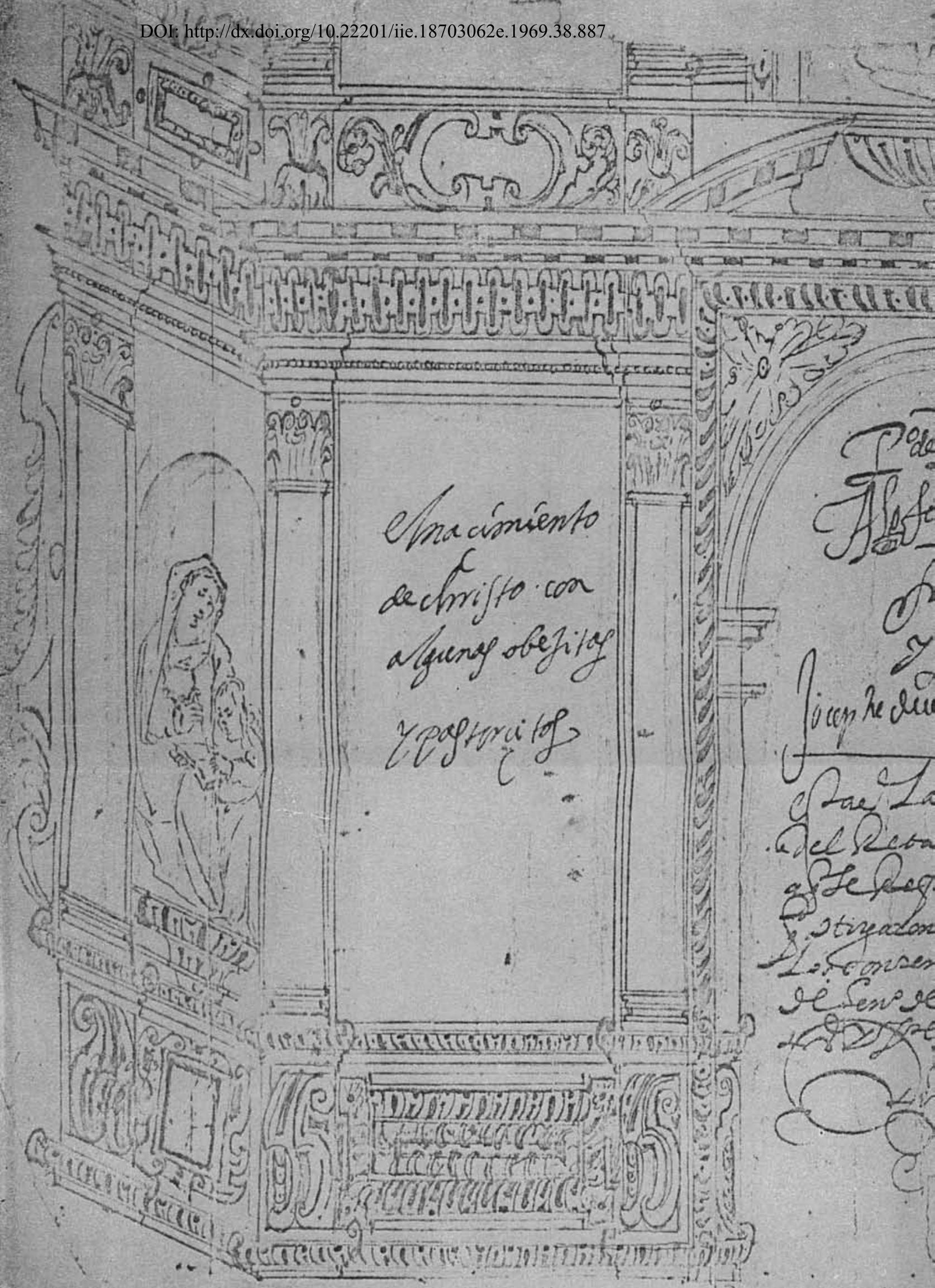


DOI: http://dx.doi.org/10.22201/iie.18703062e.1969.38.887 
enjutas hojas de acanto formando unos florones, rematando en un frontón roto, en el que penetra la repisa del tablero central. En la parte inferior de este cuerpo hay diseñada una abundante decoración con cartelas y resaltos con gallones que corresponden a las bases de las columnas. En el segundo, también las columnas son lisas con capiteles corintios, la base y el entablamento revestidos con motivos a base de cartelas, tarjas y florones. En el centro de este cuerpo, dentro de un marco con acodos que cubren las dos columnas se encuentra el tablero central, rematado por un frontón arrollado, finamente decorado que alberga un mascarón. El remate carece de las entrecalles externas y las laterales son más bajas en relación a la central, que se eleva más para rematar en un frontón clásico, que alberga, siguiendo la tradición de los retablos del siglo xvi, la figura del Padre Eterno. Este cambio en la altura de las entrecalles permite colocar lateralmente dos ángeles, que sujetan sendas cartelas manieristas, ostentando el escudo de la orden carmelita. El remate está rodeado por un coronamiento con una delgada franja decorada con pequeñas hojas de acanto y un discreto decorado a base de tableros rectangulares. Lateralmente se observan en el primer cuerpo unos alerones mixtilíneos.

La distribución de las imágenes es interesante. En el primer cuerpo en las entrecalles laterales deberían ir dos pinturas: "el nacimiento de Cristo con algunas obejitas y pastorcitos" y "la adoración de los Santos Reyes"; en los nichos laterales las esculturas de Santa Ana con la Virgen niña, que lleva un libro y al otro lado "San Onofre, carmelita". En la parte baja del lienzo derecho se indica, quizá como otra posibilidad, en un letrero, "la visitación de Santa Isabel". En el segundo cuerpo al centro San José, con el niño, flanqueado por lienzos con "La Hulda a Egipto" y al parecer "San Joaquin y la Virgen Niña"; en los nichos San Andrés, santo del nombre de uno de los benefactores del convento el capitán Andrés de Arano, y al otro lado un fraile carmelita. Finalmente en el remate, las pinturas laterales, que representan la Oración del Huerto y "la Cruz a Cuestas", flanquean un tablero con un "Calva-. rio". Aquí la preocupación por encontrar un sentido teológico a la composición del retablo se pierde, interesando sólo colocar las esculturas y las pinturas acordes de la advocación del convento, del benefactor o sólo como objeto de piadosa devoción. En líneas generales su composición es sencilla, las calles externas sobresalen, aunque esto no se aprecia en la traza por la perspectiva defectuosa, acentuando de esta 
manera el eje central al dar profundidad al retablo, que se enfatiza con el coronamiento de la parte alta.

En su composición y lineamientos generales continúa las modalidades renacentistas del siglo xvl, sin embargo las columnas de capitel corintio de fuste liso son bastante clásicas aun cuando irían "jaspeallas", marcando quizá el inicio de la tradición en el empleo de columnas de alabastro, que tanta importancia llegará a adquirir en la zona de Puebla. El empleo de las tarjas y cartelas, los frontones arrollados, aletones decoración menuda, florones y pilastrillas con agallones resaltados, le prestan un notable aire manierista, que se percibe en algunos restos de trabajos de talla en Puebla de esta época y también en las obras de fray Andrés de San Miguel. Gran parte de los elementos decorativos señalan en este retablo un momento en la evolución hacia las formas indiscutiblemente personales del Barroco Poblano, donde se transformarán en busca del movimiento y riqueza decorativa. 